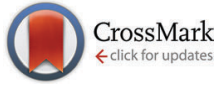

Cite this: Chem. Commun., 2015, 51,346

Received 25th September 2014, Accepted 5th November 2014

DOI: $10.1039 / c 4 c c 07574 a$

www.rsc.org/chemcomm

\section{A straightforward alkynylation of $\mathrm{Li}$ and $\mathrm{Mg}$ metalated heterocycles with sulfonylacetylenes $\dagger$}

\author{
Leyre Marzo, Ignacio Pérez, Francisco Yuste, José Alemán* and \\ José Luis García Ruano*
}

Coupling of alkynyl moieties to heterocyclic rings, without using transition metals, can be easily performed by the reaction of aryl or heteroaryl sulfonylacetylenes with heteroaryl-Li compounds or their corresponding less reactive magnesium derivatives.

Heteroarylated acetylenic structures are widespread in the field of materials science, as well as in many biologically interesting compounds $^{1}$ (Fig. 1). In the latter field, they are present in a large number of products with biological activity like carlina oxide $^{2}$ (I) with antimicrobial properties, the metabotropic glutamate receptor $\mathbf{I I},{ }^{3}$ related to the learning and memory processes,

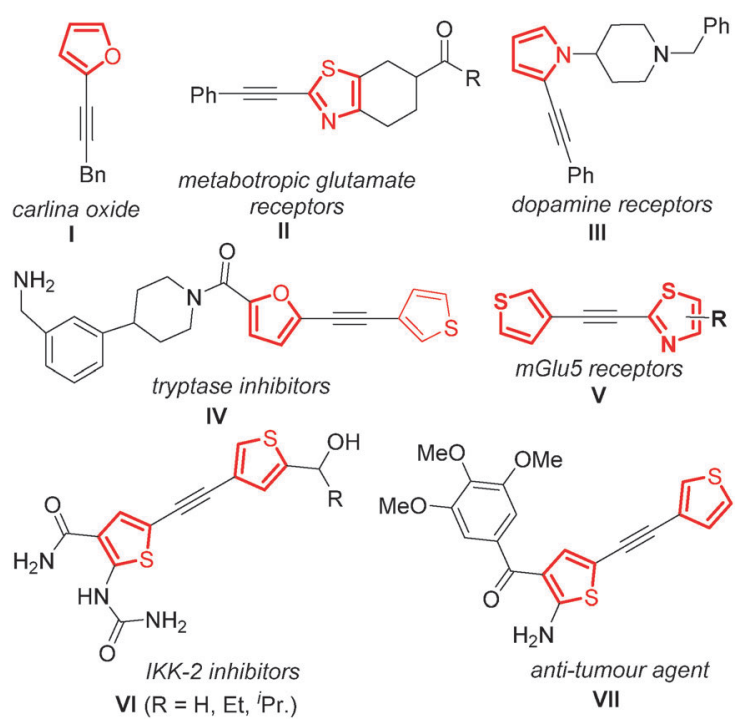

Fig. 1 Heteroaryl alkynes of biological interest.

Departamento de Química Orgánica (Módulo 1), Facultad de Ciencias, Universidad Autónoma de Madrid, Cantoblanco, 28049-Madrid, Spain.

E-mail: jose.aleman@uam.es, joseluis.garcia.ruano@uam.es;

Web: www.uam.es/jose.aleman

$\dagger$ Electronic supplementary information (ESI) available: Experimental. See DOI: $10.1039 / \mathrm{c} 4 \mathrm{cc} 07574 \mathrm{a}$ or the dopamine receptor (III) ${ }^{4}$ which is used against schizophrenia. Particularly interesting are diheteroarylated acetylenic moieties, like those containing a thienyl residue, which are also present in pharmacologically interesting compounds. Thus, thiophene and furane rings are joined to the triple bond in the tryptase inhibitor $\mathbf{I V},{ }^{5}$ used for treating allergic or inflammatory disorders, whereas thiophene and thiazole form part of the structure of the mGlu5 receptors $\mathbf{V}{ }^{6}$ In addition, the $2,3^{\prime}$ dithiophene-acetylene moiety is present in the IKK-2 inhibitor $\mathbf{V I}^{7}$ and in the anti-tumour agent VII. ${ }^{8}$

The most employed methodology for the synthesis of heteroaryl acetylenes involves the use of the well-known Sonogashira reaction, ${ }^{9}$ starting from heterocyclic halides and aryl or heteroaryl acetylenes and using palladium as the catalyst. As an alternative, the direct alkynylation of heteroaromatic compounds with alkynyl halides was developed (inverse Sonogashira) ${ }^{10}$ but it is restricted to highly activated $\mathrm{C}-\mathrm{H}$ heterocycles (e.g. thiazole). Very recently, other strategies, like the use of hypervalent iodine reagents with $\mathrm{Au}^{\mathrm{I}}$ as the catalyst ${ }^{11}$ (eqn (a), Scheme 1) and the oxidative cross-coupling of terminal alkynes with heteroarenes, ${ }^{12}$ have been reported (eqn (b), Scheme 1). However, the use of the hypervalent iodine is only valid for preparing $\operatorname{SiiPr}_{3}$ alkynyl derivatives ${ }^{11}$ and the oxidative crosscoupling $^{12}$ is mainly circumscribed to the synthesis of 2-arylalkynyl 5-substituted thiophenes (rather modest yields were obtained with furane and pyrrol derivatives). Thus, these a) Waser's work:

$X=O, N, S$
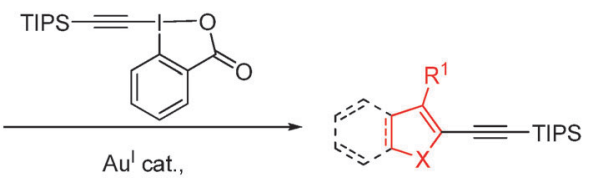
b) Su's work:
$\left.R^{1} \|^{X}\right\rangle^{c-2}$
$\mathrm{X}=\mathrm{O}, \mathrm{S}$

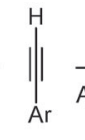

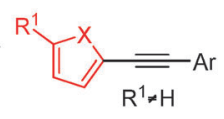

Scheme 1 Recent approaches for the direct alkynylation of heterocycles. 
methods preclude the synthesis of monosubstituted heterocycles, bearing only the alkynyl moiety, which is the case of many of the compounds shown in Fig. 1. Moreover, these alternative methods cannot be used for incorporating acetylenic chains into the less activated positions or the heterocyclic rings and therefore cannot be considered as general alternatives to the Sonogashira reaction for alkynylating heterocycles.

All these methodologies require the use of transition metals for the formation of the Csp-Csp ${ }^{2}$ bond, which was recognized as a handicap for pharmaceutical companies, ${ }^{13}$ which indicated the convenience of finding alternative methods for $\mathrm{C}-\mathrm{C}$ coupling, avoiding the use of transition metals as catalysts. In 2012, our group reported the unexpected electrophilic behavior of arylsulfonylacetylenes that undergo an unusual $\alpha$-attack (anti-Michael addition) in reactions with organolithiums, followed by elimination of the $\mathrm{ArSO}_{2}{ }^{-}$moiety to allow the alkynylation of lithiated $\mathrm{Csp}^{2}$ or $\mathrm{Csp}^{3}$ (eqn (a), Scheme 2). ${ }^{14}$ This transition-metal free methodology was applied regardless of the source of the organolithiums (alkyl-lithium derivatives ${ }^{14 b}$ or arenes with activated $\mathrm{C}-\mathrm{H}^{14 a}$ ). Our goal in this work is the use of this methodology to prepare different alkynyl heterocyles (eqn (b), Scheme 2), paying special attention to the regioselective synthesis of dialkynyl heterocycles (useful in materials science) and diheteroaryl acetylenes (present in pharmacologically interesting compounds, see Fig. 1). As some of the studied substrates were not stable in the presence of organolithiums, the behavior of the less reactive Grignard reagents was studied, which provided surprisingly good results.

We initiated our study by considering the results previously obtained in the preparation of the 2-phenylethynyl heterocycles 3Aa, 3Ba, and 3Ca (Table 1). ${ }^{14 a}$ Typically, the $\alpha$-lithiation is performed with $n$-BuLi or $t$-BuLi in THF or ether at $0{ }^{\circ} \mathrm{C}$, and the alkynylation with sulfone $1 \mathrm{a}$ at $-78{ }^{\circ} \mathrm{C}$ in $\mathrm{THF}^{15}$ Similar conditions were successfully used to prepare the alkynyl derivatives 3Da and 3Ea, from the 2-substituted furanes $2 \mathbf{D}$ and $2 \mathbf{E}$, in excellent yields (Table 1). At this point, we studied the behavior of $2 \mathbf{F}$ and observed the exclusive formation of $3 \mathbf{F a}$ in $60 \%$ yield (Table 1), evidencing that the activation provided by the thiophene was clearly higher than that of the furane ring. The preparation of other monoalkynylated heterocycles (Table 1), like those derived from $N$-methylpyrazol $(3 \mathbf{G a})$, thiazole $(3 \mathbf{H a})$, benzothiazole (3Ia), and imidazopyridine (3Ja), gave excellent yields under smooth conditions. In all the cases, the incorporation of the alkynyl residue only took place in the more activated position.

Our next step was to study the influence of the substituents at the aryl group of $p$-tolylsulfonylacetylenes $\mathbf{1 a}-\mathbf{g}$ on the reactivity

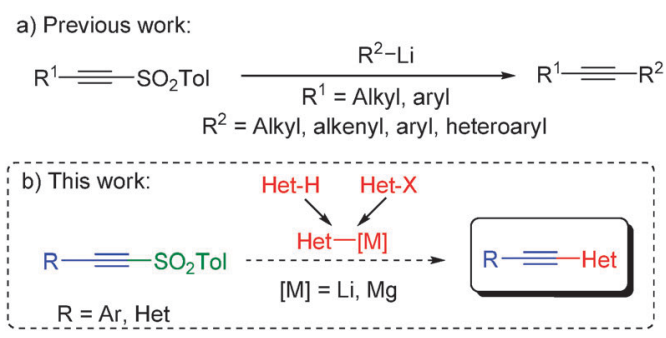

Scheme 2 Previous report and present work.
Table 1 Alkynylation of different heterocycles (2A-M) based on their $\mathrm{C}-\mathrm{H}$ activation with $t$-BuLi or $n-\mathrm{BuLi}^{\mathrm{a}}$

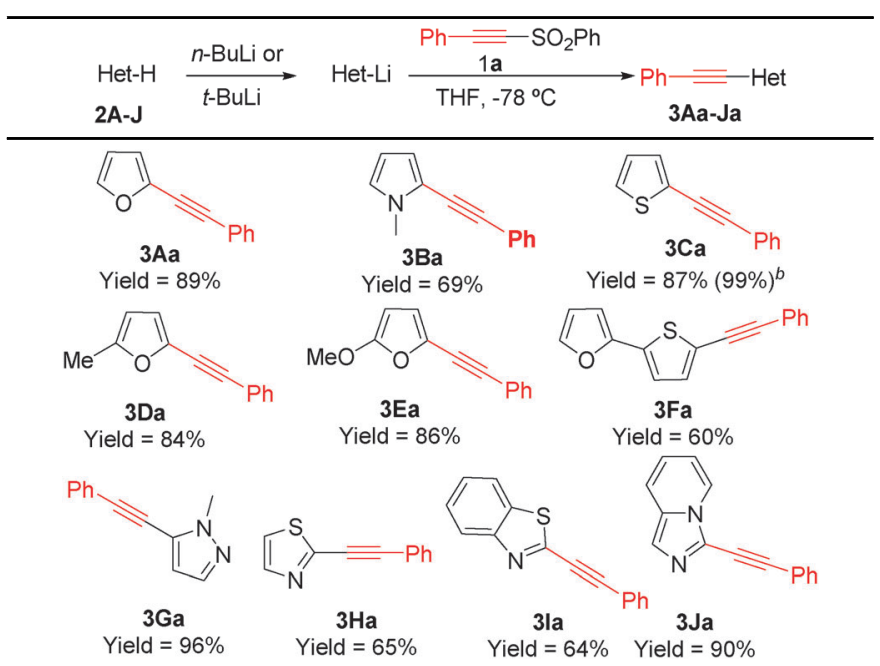

${ }^{a}$ All the reactions were performed with $0.2 \mathrm{mmol}$ of $1 \mathrm{a}$ and $0.4 \mathrm{mmol}$ of 2A-J. ${ }^{b}$ Reaction carried out at the $2.34 \mathrm{mmol}$ scale.

Table 2 Reactions of Li-2A with the $p$-tolylsulfonylacetylenes $\mathbf{1} \mathbf{a}-\mathbf{g}^{\mathbf{a}}$

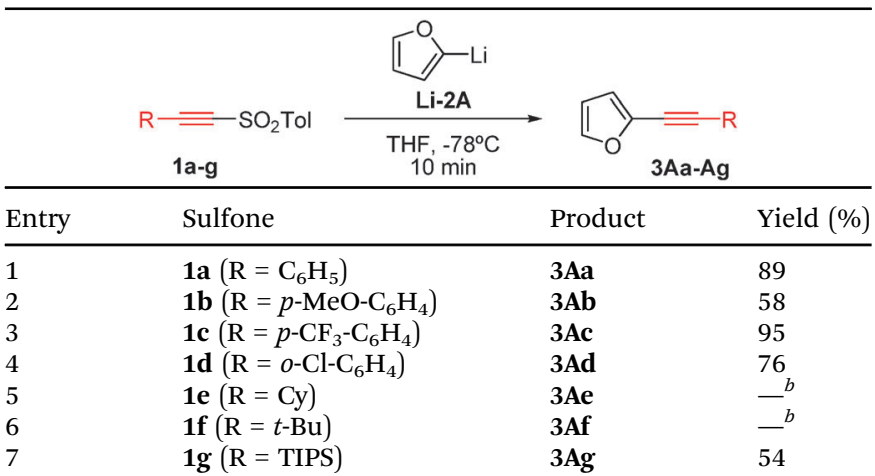

${ }^{a}$ All the reactions were performed with $0.2 \mathrm{mmol}$ of $\mathbf{1 a - g}$ and $0.4 \mathrm{mmol}$ of 2 A. ${ }^{b}$ Reaction mixtures mainly containing Michael addition products.

of the anti-Michael addition. For this study 2-Li furan (Li-2A) was chosen to react with different alkynylsulfones under standard conditions shown in Table $1\left(\mathrm{THF},-78{ }^{\circ} \mathrm{C}\right)$ in a 10 min reaction (Table 2). Electron donating groups decreased the reactivity ( $58 \%$ yield of $3 \mathbf{A b}$, compare entries 1 and 2), whereas electronwithdrawing groups increased it (95\% yield of 3Ac, compare entries 1 and 3), which is not unexpected taking into account the effect of these groups on the electrophilic character of the triple bond. The reaction was also compatible with the presence of ortho-substituents ( $76 \%$ yield of 3Ad, entry 4). The donating character of the alkyl groups could explain the failure of the reactions with $\mathbf{1 e}$ and $\mathbf{1 f}$ to obtain the anti-Michael products 3Ae and 3Af (entries 5 and 6). The negative influence of the steric effects of these substituents must be less relevant because the even larger TIPS group, present at $\mathbf{1 g}$, was not a handicap in its reaction with Li-2A (3Ag is formed in $54 \%$ yield, entry 7), probably due to its favourable electronic effects (see later). Compound 3Ag is important because it can be deprotected and functionalized, thus making possible the preparation of alkyl acetylenes that cannot be obtained by direct reaction. 


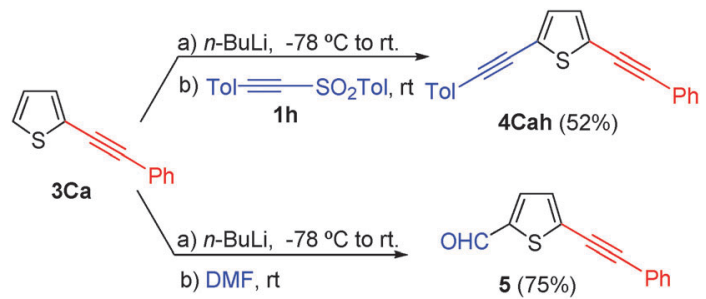

Scheme 3 Functionalization of monoalkynyl heterocycles.

The absence of 2,5-dialkynylfuranes in the reaction mixtures obtained from unsubstituted heterocycles 2 (Tables 1 and 2) suggests the lower reactivity of their monoalkynyl derivatives 3 and allows their use as starting materials in subsequent functionalization processes based on the $\mathrm{C}-\mathrm{H}$ activation of the other $\alpha$-position $(\mathrm{C}-5){ }^{16}$ In this sense, starting from $3 \mathrm{Ca}$, we were able to prepare 2,5-dialkynylthiophenes like 4Cah, bearing two different acetylenic moieties at the activated positions (eqn (b), Scheme 3), which are not easily obtained with other methodologies. The introduction of other electrophiles like $\mathrm{CHO}$ by reaction with DMF ( 5 in Scheme 3 ) was also possible. In both cases, the reactions of the monoalkynyl thiophene 3Ca with the electrophiles were performed at it (at lower temperatures the reactions did not work), which revealed its lower reactivity with respect to the unsubstituted thiophene $2 \mathrm{C}$, which could be alkynylated at $-78{ }^{\circ} \mathrm{C}$, as was indicated in Table 1 .

At this point, we investigated the possibilities of our reaction for introducing the alkynyl moieties into the non-activated positions of the heterocycles, starting from the appropriate haloderivative and generating the corresponding organolithium by lithium-halogen exchange. Thus, starting from 3-bromothiophene (2K), the $\mathrm{Li}-\mathrm{Br}$ exchange with $n$-BuLi took place quickly (less than 15 minutes) at $-78{ }^{\circ} \mathrm{C}$ (Scheme 4 ) and was followed by the addition of $1 \mathrm{a}$ at $-78{ }^{\circ} \mathrm{C}$ that cleanly afforded $3 \mathrm{Ka}$ in almost quantitative yield. ${ }^{17}$

The incorporation of a second alkynyl group in the heteroaryl ring of 3Ka with two activated C-H heterocycles (at C-2 and C-5) would yield dialkynyl thiophenes, the formation of two regioisomers being possible. To our delight, deprotonation of 3Ka with $n$-BuLi at $-78{ }^{\circ} \mathrm{C}$, followed by reaction with the sulfone $\mathbf{1 h}$ at $\mathrm{rt}$, only yielded the 2,3-dialkynyl derivative 4 Kah $(57 \%$ yield) in a completely regioselective way. The reactivity of $3 \mathrm{Ka}$ and $3 \mathrm{Ca}$, both monoalkynyl derivatives, was lower (reactions with $\mathbf{1}$ require rt) than that of the thiophene $\mathbf{2 C}$ (reaction with 1 took place at $-78{ }^{\circ} \mathrm{C}$ ). However, the formation of the organolithiums from $3 \mathbf{K a}$ and $3 \mathrm{Ca}$ was easier $\left(-78^{\circ} \mathrm{C}\right)$ than from $3 \mathrm{C}$ $\left(0{ }^{\circ} \mathrm{C}\right.$ to rt $) .{ }^{18}$ This suggests a stabilizing influence of the alkynyl group on the organolithium, which decreases its reactivity. ${ }^{19}$ The properties and reactivity associated with the spatial proximity of the two acetylenic moieties on $\mathrm{C}-2$ and $\mathrm{C}-3$ of the thiophene ring have been useful in materials science and bionatural products. ${ }^{20}$

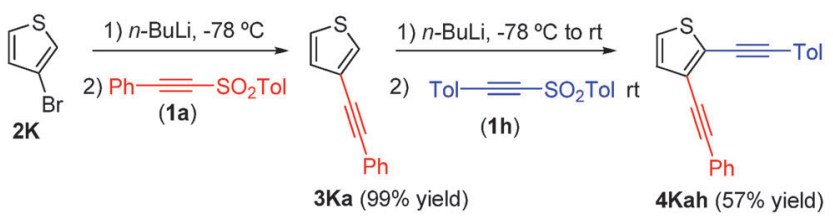

Scheme 4 Double alkynylation of 3-bromo thiophene.

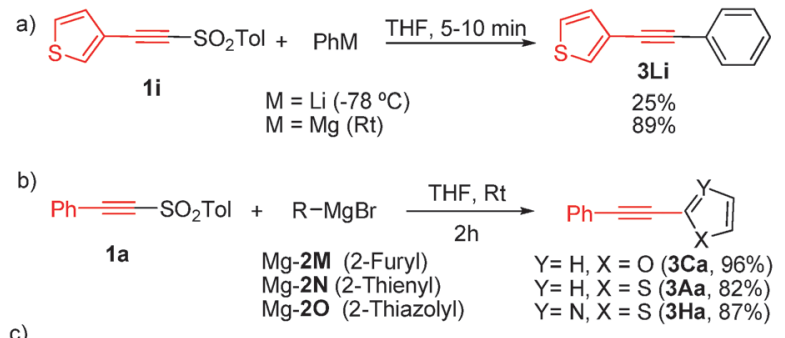

c)

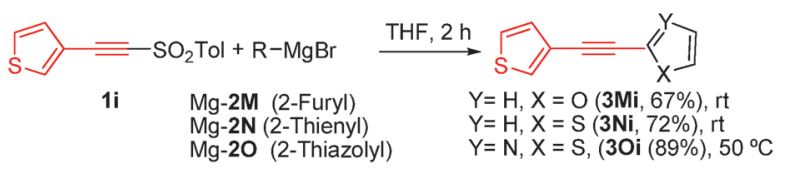

Scheme 5 Reaction of sulfones $1 \mathrm{a}$ and $1 \mathbf{i}$ with Grignard compounds.

Once we checked the potential of our method in the synthesis of heteroaryl aryl acetylenes, our next goal was to obtain diheteroaryl acetylenes. The synthesis of these compounds required the preparation of heteroaryl alkynyl sulfones to be used as starting products in reactions with the heteroaryllithiums. We focus our attention on sulfones containing the thiophene ring, like $\mathbf{1 i},{ }^{21}$ which would give access to the skeleton of the diheteroaryl acetylenes IV-VII shown in Fig. 1. Reaction of $1 \mathbf{i}$ with $\mathrm{PhLi}(\mathrm{Li}-2 \mathrm{~L})$ at $-78{ }^{\circ} \mathrm{C}$ in THF provided the expected acetylene $3 \mathrm{Ka}$, but in low yield (25\%), along with a large number of unidentified byproducts (eqn (a), Scheme 5). Reactions with other heteroaryllithiums derived from $\mathbf{2} \mathbf{M}-\mathbf{2 O}$ were even less fruitful. These results suggest that $1 \mathrm{i}$ is not stable in the presence of organolithiums. Taking into account that Grignard reagents are less reactive and, in some cases, more selective too than organolithium compounds, ${ }^{22}$ we studied the reaction of $1 \mathbf{i}$ with $\mathrm{PhMgCl}(\mathbf{M g}-2 \mathrm{~L})$. The reaction did not work at $-78{ }^{\circ} \mathrm{C}$ and $0{ }^{\circ} \mathrm{C}$ but 3 Ka was afforded in an excellent $89 \%$ yield when it was conducted at rt (eqn (a), Scheme 5). Then we explored the reactivity of different heteroaryl Grignard derivatives (Mg-2M-O) with the phenylethynylsulfone 1a. These reactions were very clean in all the cases (only one product was detected by NMR in the reaction crudes) yielding alkynes 3Aa, 3Ca, and 3Ha in excellent yields after $2 \mathrm{~h}$ at rt (eqn (b), Scheme 5). This reveals that the Grignard reagents, working at rt, are as efficient as the organolithiums at $-78{ }^{\circ} \mathrm{C}$ in their anti-Michael reactions with alkynyl sulfones. Thus, Grignard compounds $\mathbf{M g}-2 \mathbf{M}, \mathbf{M g}-2 \mathbf{N}$, and $\mathbf{M g}-2 \mathrm{O}$ provided the corresponding diheteroaryl acetylenes (3Mi and $3 \mathrm{Ni}$ at rt and 3Oi at $50{ }^{\circ} \mathrm{C}$ ) in good yields (decomposition products were not detected), which confirmed the potential of our methodology to prepare diheteroaryl acetylenes (eqn (c), Scheme 5).

The mechanism proposed for the anti-Michael reactions of RLi with substituted sulfonylacetylenes ${ }^{15}$ (Scheme 6), supported by theoretical calculations, involves the association of the lithium with the sulfinyl oxygens as the previous step of the intramolecular $\alpha$-attack of the R group on the triple bond and the subsequent elimination of the metal sulfonate (Scheme 6). The ability of the $\mathrm{R}^{\prime}$ to stabilize the carbanionic intermediate would explain the behaviour of the different substrates shown in Table 2. The lower reactivity and chelating ability of Grignard derivatives $\mathrm{Mg}-2$ with respect to those of Li-2 could show that the first ones require higher temperatures to obtain good conversions. Moreover, these differences in reactivity also support the nucleophilic character of the $\alpha$-attack. ${ }^{23}$ 


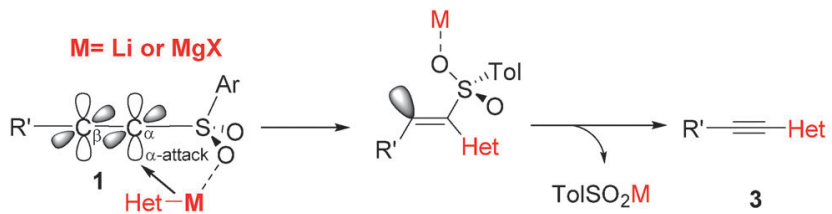

Scheme 6 Mechanistic proposal for the reaction of sulfonylacetylenes 1 with organolithium and organomagnesium reagents.

In conclusion we have demonstrated that the anti-Michael addition of $\mathrm{RLi}$ or $\mathrm{R}-\mathrm{Mg} \mathrm{X}^{24}$ to sulfonylacetylenes constitutes an efficient methodology to obtain different aryl-heteroaryl and diheteroaryl acetylenes under very mild conditions. The broad scope, excellent yields, and simplicity of the experimental procedure, which does not require transition metals, are the main features of this methodology. The present work can be considered as a general alternative to the Sonogashira reaction in alkynylation reactions of heterocycles without using transition metals.

Financial support from the Spanish Government (CTQ201235957) is gratefully acknowledged. J. A. thanks the MICINN for a "Ramon y Cajal" contract. I. P. thanks Conacyt-México for a predoctoral fellowship and F. Y. thanks Conacyt-México and DGAPA-UNAM for a sabbatical fellowship. L. M. thanks the Spanish government for a FPU fellowship.

\section{Notes and references}

1 Acetylene Chemistry: Chemistry, Biology and Material Science, ed. F. Diederich, P. J. Stang and R. R. Tykwinski, Wiley-VCH, Weinheim, 2005.

2 F. Herrmann, R. Hamoud, F. Sporer, A. Tahrani and M. Wink, Planta Med., 2011, 77, 1905.

3 M. Packiarajan, M. Grenon, S. Zorn, A. T. Hopper, A. D. White, G. Chandrasena, X. Pu, R. M. Brodbeck and A. J. Robichaud, J. Med. Chem., 2013, 23, 4037.

4 C. Haubmann, H. Hübner and P. Gmeiner, J. Med. Chem. Lett., 1999, 9, 3143.

5 M. J. Costanzo, S. C. Yabut, H.-C. Zhang, K. B. White, L. de Garavilla, Y. Wang, L. K. Minor, B. A. Tounge, A. N. Barnakov, F. Lewandowski, C. Milligan, J. C. Spurlino, W. M. Abraham, V. Boswell-Smith, C. P. Pagec and B. E. Maryanoff, J. Med. Chem. Lett., 2008, 18, 2114.

6 A. Hopper, A. Sams, M. Graven, K. Gitte, M. Packiarajan and M. Grenon, US Pat. Appl. Publ., US 20110092475 A1 20110421, 2011.

7 D. Bonafoux, S. Bonar, L. Christine, M. Clare, A. Donnelly, J. Guzova, N. Kishore, P. Lennon, A. Libby, S. Mathialagan, W. McGhee, S. Rouw, C. Sommers, M. Tollefson, C. Tripp, R. Weier, S. Wolfson and Y. Min, Bioorg. Med. Chem. Lett., 2005, 15, 2870.

8 (a) R. Romagnoli, P. G. Baraldi, O. Cruz-Lopez, M. Tolomeo, A. Di Cristina, R. M. Pipitone, S. Grimaudo, J. Balzarini, A. Brancale and E. Hamel, Bioorg. Med. Chem. Lett., 2011, 21, 2746; (b) G. Liang, S. Aldous, G. Merriman, J. Levell, J. Pribish, J. Cairns, X. Chen, S. Maignan, M. Mathieu, J. Tsay, K. Sides, S. Rebello, B. Whitely, I. Morize and H. W. Pauls, Bioorg. Med. Chem. Lett., 2012, 22, 1049. 9 For recent reviews, see: (a) H. Doucet and J.-C. Hierso, Angew. Chem., Int. Ed., 2007, 46, 834; (b) R. Chinchilla and C. Nájera, Chem. Soc. Rev., 2011, 40, 5084.

10 (a) S. H. Kim and S. Chang, Org. Lett., 2010, 12, 1868; (b) A. S. Dudnik and V. Gevorgyan, Angew. Chem., Int. Ed., 2010, 49, 2096; (c) A. S. Dudnik and V. Gevorgyan, Eur. J. Org. Chem., 2010, 6495; (d) I. V. Seregin, V. Ryabova and V. Gevorgyan, J. Am. Chem. Soc., 2007, 129, 7742; $(e)$ Y. Gu and X.-M. Wang, Tetrahedron Lett., 2009, 50, 763; $(f)$ N. Matsuyama, K. Hirano, T. Satoh and M. Miura, Org. Lett., 2009, 11, 4156; $(g)$ F. Besselièvre and S. Piguel, Angew. Chem., Int. Ed., 2009, 48, 9553.

11 (a) J. P. Brand, J. Charpentier and J. Waser, Angew. Chem., Int. Ed., 2009, 48, 9346; (b) J. P. Branda and J. Waser, Angew. Chem., Int. Ed., 2010, 49, 7304; (c) Y. Li and J. Waser, Beilstein J. Org. Chem., 2013,
9, 1763. For a review on the electrophilic alkynylation of the same group, see: J. P. Branda and J. Waser, Chem. Soc. Rev., 2012, 41, 4165.

12 (a) X. Jie, Y. Shang, P. Hu and W. Su, Angew. Chem., Int. Ed., 2013, 125, 3718; (b) For other related reactions with indoles, see: L. Yang, L. Zhao and C.-J. Li, Chem. Commun., 2010, 46, 4184.

13 D. J. C. Constable, P. J. Dunn, J. D. Hayler, G. R. Humphrey, J. L. Leazer Jr., R. J. Linderman, K. Lorenz, J. Manley, B. A. Pearlman, A. Wells, A. Zaks and T. Y. Zhang, Green Chem., 2007, 9, 411.

14 (a) J. L. García Ruano, J. Alemán, L. Marzo, C. Alvarado, M. Tortosa, S. Díaz-Tendero and A. Fraile, Angew. Chem., Int. Ed., 2012, 51, 2712; (b) J. L. García Ruano, J. Alemán, L. Marzo, C. Alvarado, M. Tortosa, S. Díaz-Tendero and A. Fraile, Chem. - Eur. J., 2012, 18, 8414.

15 These yields were obtained starting from $0.2 \mathrm{mmol}$ of $2 \mathrm{~A}-2 \mathrm{C}$ but the reaction can be scaled up (3Ca was obtained in 95\% yield on a $2.34 \mathrm{mmol}$ scale).

16 Other $\mathrm{C}-\mathrm{H}$ functionalizations are not selective strategies and a mixture of the two activated positions would be found. Therefore, only substituted thiophenes in the 2 position (with the $2^{\prime}$ position free to be activated) can be used as starting materials (see e.g. ref. 12).

17 The standard reaction time for the $\mathrm{Br}-\mathrm{Li}$ exchange process was 15 minutes. Longer reaction times for the $\mathrm{Br}-\mathrm{Li}$ exchange gave equilibria of $3-\mathrm{Li}-2 \mathrm{~K}$ and $2-\mathrm{Li}-2 \mathrm{~K}$, and consequenly the corresponding mixture of monoalkynyl derivatives was formed.

18 This was confirmed by studying deuteration reactions at $-78{ }^{\circ} \mathrm{C}$ of the $\mathrm{Li}$ carbaniones generated from $3 \mathrm{Ca}$ and $3 \mathrm{Ka}$ at the same temperature. This results in the exclusive formation of the 5-D and 2-D derivatives respectively. The reaction of thiophene with $n$-BuLi at $-78{ }^{\circ} \mathrm{C}$ only yielded decomposition products, presumably due to the opening of the ring with the organolithium (see e.g. K. Chernichenko, N. Emelyanov, I. Gridnev and V. G. Nenajdenko, Tetrahedron, 2011, 67, 6812), whereas the reaction at $0{ }^{\circ} \mathrm{C}$ produces its 2 -Li derivative (unsensitive to the opening), which is quantitatively deuterated with $\mathrm{ND}_{4} \mathrm{Cl}$.

19 It can be explained by assuming an -I effect of the alkynyl group (weaker for longer distance) that stabilizes the lithium carbanion but reduces its reactivity. The complete regioselectivity observed in the alkynylation reaction of 3Ka indicates that this stabilization is clearly higher for $\mathrm{C}(2)-\mathrm{Li}$ than for C(5)-Li, which supports the above statement. Another possible explanation of this regioselectivity would involve the formation of a mixture of $\mathrm{C}(2)-\mathrm{Li}$ and $\mathrm{C}(5)-\mathrm{Li}$ derivatives of 3Ka, with the first one being the most reactive. Nevertheless this could be discarded by the exclusive deuteration at C-2 observed by protonation with $\mathrm{ND}_{4} \mathrm{Cl}$ (see ref. 18).

20 For materials science, see: (a) P.-L. T. Boudreault, J. W. Hennek, S. Loser, R. Ponce Ortiz, B. J. Eckstein, A. Facchetti and T. J. Marks, Chem. Mater., 2012, 24, 2929; (b) M. J. O'Connor, R. B. Yelle, L. N. Zakharov and M. M. Haley, J. Org. Chem., 2008, 73, 4424. For organic synthesis, see: (c) S. Naoe, Y. Suzuki, K. Hirano, Y. Inaba, S. Oishi, N. Fujii and H. Ohno, J. Org. Chem., 2012, 77, 4907; (d) M. M. Hansmann, M. Rudolph, F. Rominger, A. Stephen and K. Hashmi, Angew. Chem., Int. Ed., 2013, 52, 2593.

21 Sulfone 1i was prepared in two steps from the commercially available 3-ethynyl thiophene by reaction with sodium toluene sulfinate and $\mathrm{NaI}$ in the presence of CAN, followed by reaction with $\mathrm{K}_{2} \mathrm{CO}_{3}$ in refluxing acetone, according to the procedure reported by Nair et al. (V. Nair, A. Augustine and T. D. Suja, Synthesis, 2002, 2259). Other heteroarylsulfonyl acetylenes could not be prepared by this procedure, because the starting ethynyl derivatives are not commercially available. We have tried to prepare them, but in the isolation step we found serious problems due to their high volatility.

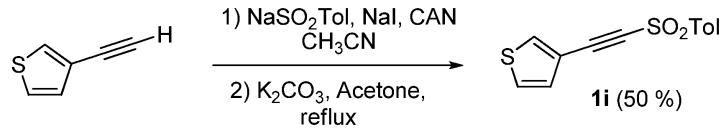

22 (a) P. Knochel, W. Dohle, N. Gommermann, F. F. Kneisel, F. Kopp, T. Korn, I. Sapountzis and V. A. Vu, Angew. Chem., Int. Ed., 2003, 42, 4302; (b) H. Ila, O. Baron, A. J. Wagner and P. Knochel, Chem. Commun., 2006, 583. For a precedent of the alkylation of Grignards with alkynyl sulfones, see: R. L. Smorada and W. E. Truce, J. Org. Chem., 1979, 44, 3444.

23 The radical character suggested for the $\alpha$-addition would not explain the lower reactivity of the Grignard derivatives (see: J. L. García Ruano, J. Alemán, A. Parra and L. Marzo, Eur. J. Org. Chem., 2014, 1577).

24 We are currently working on a full article concerning the use of the Grignard reagents in alkynylation reactions with sulfonyl acetylenes, which will be published in the near future. 